\title{
Medication errors in paediatric outpatients
}

\author{
Rainu Kaushal, ${ }^{1,2,3}$ Donald A Goldmann, ${ }^{5,6}$ Carol A Keohane, ${ }^{4}$ \\ Erika L Abramson, ${ }^{1,2}$ Seth Woolf, ${ }^{4}$ Catherine Yoon, ${ }^{4}$ \\ Katherine Zigmont, ${ }^{4}$ David W Bates ${ }^{4,7,8}$
}

${ }^{1}$ Department of Medicine, Weill Medical College of Cornell University, New York, USA ${ }^{2}$ Department of Public Health, Weill Medical College of Cornell University, New York, USA ${ }^{3}$ Department of Pediatrics, Weill Medical College of Cornell University, New York, USA ${ }^{4}$ Division of General Internal Medicine, Brigham and Women's Hospital, Boston, Massachusetts, USA ${ }^{5}$ Department of Medicine, Children's Hospital, Boston, Massachusetts, USA ${ }^{6}$ Institute for Healthcare Improvement, Cambridge, Massachusetts, USA

${ }^{7}$ Harvard Medical School, Boston, Massachusetts, USA ${ }^{8}$ Information Systems, Partners Healthcare System, Boston, Massachusetts, USA

Correspondence to Dr Rainu Kaushal, Departments of Pediatrics and Public Health, Weill Medical College of Cornell University, 402 E 67th Street, Rm LA-261, New York, NY 10065, USA;

rak2007@med.cornell.edu

Accepted 9 May 2010 Published Online First 10 August 2010

\section{ABSTRACT}

Background Medication errors are common in many settings and have important ramifications. Although there is growing research on rates and characteristics of medication errors in adult ambulatory settings, less is known about the paediatric ambulatory setting.

Objective To assess medication error rates in paediatric patients in ambulatory settings.

Methods The authors conducted a prospective cohort study of paediatric patients in six outpatient offices in Massachusetts. Data were collected using duplicate prescription review, two parental surveys and chart review. A research nurse classified all medication errors by stage and type of error.

Results The authors identified 1205 medication errors with minimal potential for harm (rate: $68 \%$ of patients, $95 \% \mathrm{Cl} 64$ to $72 \%$; 53\% of $\mathrm{Rx}, 95 \% \mathrm{Cl} 50$ to $56 \%$ ) and 464 potentially harmful medication errors (ie, near misses) (rate: $26 \%$ of patients, $95 \% \mathrm{Cl} 24$ to $28 \% ; 21 \%$ of $\mathrm{Rx}, 95 \% \mathrm{Cl} 19$ to $22 \%$ ). Overall, $94 \%$ of the medication errors with minimal potential for harm and $60 \%$ of the near misses occurred at the prescribing stage. The most common types of errors were inappropriate abbreviations followed by dosing errors. The most frequent cause of errors was illegibility.

Conclusion With paper prescribing, half the prescriptions had medication errors, and one in five had a potentially harmful error. These rates are very high. Interventions targeting the ordering and administration stages have the greatest potential benefit.

\section{BACKGROUND}

Medical errors are common. Forty per cent of American adults report experiencing a medical error. ${ }^{1}$ Medication errors appear to be the most frequent type of medical error. The epidemiology of medication

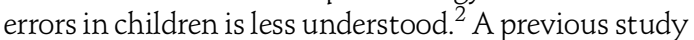
by the authors found that $5.7 \%$ of paediatric inpatients experienced a medication error, and the rate of near misses was three times higher than in adults. ${ }^{2} 3$ Factors that make children vulnerable include the need for weight-based dosing, their decreased communication ability and the particular vulnerability of babies with immature renal and hepatic systems.

Most prescription writing occurs in the outpatient setting, and errors in this setting are common. ${ }^{4} \mathrm{~A}$ study by the authors found that an adverse drug event (ADE) occurred in 16\% of children treated in the outpatient setting. ${ }^{6}$ A given patient frequently experienced more than one error or $\mathrm{ADE}$. Most occurred at the administration or ordering stages and were judged to be preventable.

While studies have evaluated harmful errors in the outpatient paediatric setting, little is known about rates of paediatric medication errors without resultant harm. ${ }^{6}$

All medication errors, regardless of whether or not they cause patient harm in a specific instance, are often a part of a cascade of those events that lead to patient harm, and we can identify systematic problems in the medication process through characterisation of these errors. It remains unclear if non-harmful errors are similar to or predictive of potentially harmful errors, and we undertook this epidemiological study to help provide a better understanding of the differences between nonharmful and potentially harmful medication errors We conducted a multioffice prospective cohort study of paediatric medication errors in the ambulatory setting. We assessed the stages at which medication errors occurred, the types of errors and the types of medications associated with errors.

\section{METHODS}

\section{Study sites}

We enrolled six paediatric outpatient offices, with two at teaching hospitals, two in urban neighbourhoods and two in affluent suburban areas. During the study period, 132 paediatric healthcare providers prescribed at these practices. All sites were using handwritten prescriptions, which we collected over a consecutive 2-month block at each practice from July 2002 to April $2003 .{ }^{6}$

\section{Definitions}

In accordance with the Institute of Medicine definition, ${ }^{7}$ medication errors were defined as errors in medication ordering, transcribing, dispensing, administering or monitoring. We further classified medication errors as errors with minimal potential for harm and near misses. For brevity, we refer to medication errors with minimal potential for harm as medication errors throughout this manuscript. An example of a medication error was prescribing a topical cream without specifying the route of administration. Near misses were medication errors with potential for harm that were either intercepted or actually reached the patient and fortuitously did not result in harm. An example was prescribing penicillin for a patient with a known penicillin allergy, but a pharmacist intercepted the prescription. Finally, rule violations were departures from strict standards of prescribing that are nevertheless well understood and were not counted as errors. Rule violations are included in the study because they are not completely appropriate prescriptions, and ideally we hope to eliminate them as well.

Preventable ADEs were medication errors that actually caused harm, while non-preventable ADEs 
were those that were not associated with a medication error. ${ }^{6}$ We do not report rates of $\mathrm{ADE}$ in this manuscript.

\section{Data collection}

Data were collected through a prescription review, telephone survey and chart review. Prescribing information was collected via duplicate prescription pads. A research nurse reviewed all duplicate prescriptions for medication errors. Data collected included medication name, dose, route, category of drug, stage when error occurred and reason for error. This methodology has been previously validated by the investigators. ${ }^{2} 589$ Prescriptions ordered by telephone or facsimile were excluded.

Surveys were used to collect data on medication errors that occurred during the transcribing, dispensing and administration processes. Ten days after the index visit, a researcher conducted a follow-up survey. Participants were questioned about the medications prescribed, potential side effects, method of administration and communication with healthcare providers, along with demographic information. The survey contents and process are further described in an earlier manuscript. ${ }^{6}$ Three months after the index visit, research nurses performed office chart reviews to detect evidence of any sequelae from medication errors and adverse drug events.

\section{Inclusion criteria}

All prescriptions except non-medication related prescriptions (ie, equipment or formula) were subject to review, but survey participants were subject to inclusion/exclusion criteria. Inclusion criteria included age less than 21 and receipt of at least one prescription at a visit. Each patient could be eligible only once. Exclusion criteria were: patients with second visits or with a sibling already participating in the study to decrease parental survey burden, requests from prescribing physicians to exclude some patients, patients without a working phone, and patients whose parents did not speak English, Spanish or Cambodian. Prescriptions for oral contraceptives, potential treatment of sexually transmitted diseases and equipment were also excluded for patient privacy reasons. ${ }^{6}$ Only data from patients who had prescriptions reviewed and participated in the survey were included to ensure completeness of cases.

\section{Classification of errors}

We classified all medication errors according to the stage of the medication process during which the error occurred, and by medication category.

\section{Incident classification}

Research nurses reviewed all prescriptions for medication errors. Suspected near misses were reviewed by two physicians. Each reviewer independently classified each event as a medication error with minimal potential for harm, near miss, $\mathrm{ADE}$ or exclusion, using a rating and classification methodology that has been previously validated. ${ }^{2} 89$ The physician reviewers then rated each event as to the severity or potential severity of injury to the patient and its preventability. Of note, all medication errors are judged to be preventable. Therefore, all events reported in this manuscript are preventable. The $\kappa$ statistics for inter-rater reliability were 0.89 for classification of event, 0.75 for severity of event and 0.95 for preventability of event.

\section{Statistical analysis}

We report the rates of medication errors per 100 patients and per 100 prescriptions with $95 \%$ CIs, and the rates of medication errors according to stage, type and medication category. Illegibility errors were analysed separately. These errors occur very frequently and are easily addressed with very basic prescribing systems. The SAS statistical package was utilised for all analyses (SAS Institute, Cary, North Carolina). This work was approved by the Partners Human Research Committee of the Partners Healthcare System of Boston, Massachusetts, USA.

\section{RESULTS}

Providers

In total, 132 paediatric providers participated in the study. Eighty-nine providers $(67 \%)$ were female (table 1$)$. The mean age was 39.8 . Of note, $50 \%$ of prescribers were residents, $40 \%$ were staff physicians, and $10 \%$ were nurse practitioners.

\section{Patients}

Thirteen thousand nine hundred and nineteen patients visited participating medical practices, and 3838 (28\%) received a prescription. Of those receiving a prescription, 2831 (74\%) were eligible for the survey, 328 opted out, and 1782 completed the initial survey (63\% response rate). Among participating patients, 2259 prescriptions were written (1.3 prescriptions per patient). Further details of the providers and survey respondents have been previously described. ${ }^{6}$

\section{Rates of medication errors}

During the study period, 1669 medication errors were identified in 1782 patients with 2259 prescriptions (74 medication errors per 100 prescriptions). After categorisation of errors, we identified 1205 medication errors with minimal potential for harm and 464 near misses. Of errors with minimal potential for harm, $94 \%$ were found by prescription review and $6 \%$ were found by survey. Fifty-eight per cent of near misses were found by prescription review, and $42 \%$ were found by survey. Of the 1782 patients, $57 \%$ experienced at least one error. Among 2259 prescriptions, $57 \%$ had at least one error.

\section{Demographic differences in medication error rates}

In general, there were very few differences among patients who experienced a medication error a near miss, or neither (table 2 ). There

Table 1 Characteristics of office practices and healthcare providers

\begin{tabular}{lccccccc}
\hline $\begin{array}{l}\text { Office } \\
\text { practice }\end{array}$ & $\begin{array}{l}\text { Paediatric } \\
\text { providers }\end{array}$ & $\begin{array}{l}\text { Staff } \\
\text { physicians } \\
(\mathbf{n}(\%))\end{array}$ & $\begin{array}{l}\text { Residents } \\
(\mathbf{n}(\%))\end{array}$ & $\begin{array}{l}\text { Nurse } \\
\text { practitioners } \\
(\mathbf{n}(\%))\end{array}$ & $\begin{array}{l}\text { Female } \\
(\mathbf{n}(\%))\end{array}$ & $\begin{array}{l}\text { Mean years } \\
\text { post- training }\end{array}$ & $\begin{array}{l}\text { Mean } \\
\text { age }\end{array}$ \\
\hline A & 7 & $6(86)$ & $0(0)$ & $1(14)$ & $5(71)$ & 10.25 & 40.0 \\
B & 11 & $6(55)$ & $5(45)$ & $0(0)$ & $10(91)$ & 9.5 & 36.6 \\
C & 88 & $22(25)$ & $58(66)$ & $8(9)$ & $60(68)$ & 10.1 & 34.2 \\
D & 9 & $6(67)$ & $3(33)$ & $0(0)$ & $3(33)$ & 14.6 & 36.7 \\
E & 11 & $8(73)$ & $0(0)$ & $3(27)$ & $8(73)$ & 15.4 & 46.5 \\
F & 6 & $5(83)$ & $0(0)$ & $1(17)$ & $3(50)$ & 10.5 & 45.0 \\
Total & 132 & $53(40)$ & $66(50)$ & $13(10)$ & $89(67)$ & 11.7 & 39.8 \\
\hline
\end{tabular}


Table 2 Patient demographics by type of medication error*

\begin{tabular}{|c|c|c|c|c|}
\hline & $\begin{array}{l}\text { Errors with minimal } \\
\text { potential }(\mathrm{n}(\%))\end{array}$ & $\begin{array}{l}\text { Near misses } \\
(\mathrm{n}(\%))\end{array}$ & $\begin{array}{l}\text { No error } \\
\text { (n }(\%))\end{array}$ & p Value $†$ \\
\hline \multicolumn{5}{|c|}{ Medication errors with minimal potential for harm } \\
\hline Total & $792(100)$ & $372(100)$ & $618(100)$ & - \\
\hline \multicolumn{5}{|l|}{ Gender } \\
\hline Female & 377 (48) & $193(52)$ & $324(52)$ & 0.15 \\
\hline \multicolumn{5}{|l|}{ Age } \\
\hline Neonates & $14(2)$ & $8(2)$ & $27(4)$ & 0.36 \\
\hline Infants & $211(27)$ & $103(28)$ & $147(24)$ & \\
\hline Toddlers & $244(31)$ & $122(33)$ & $181(29)$ & \\
\hline School age & $280(35)$ & 117 (32) & $195(32)$ & \\
\hline Adolescents & $43(5)$ & $22(6)$ & $66(11)$ & \\
\hline \multicolumn{5}{|l|}{ Race/ethnicity } \\
\hline White & $394(51)$ & $168(47)$ & 294 (49) & 0.28 \\
\hline Black & $113(15)$ & $53(15)$ & $106(18)$ & \\
\hline Hispanic & $165(21)$ & $83(23)$ & $109(18)$ & \\
\hline Other & $103(13)$ & $52(15)$ & $91(16)$ & \\
\hline \multicolumn{5}{|l|}{ Insurance } \\
\hline Medicaid & $113(14)$ & $52(14)$ & $56(9)$ & 0.008 \\
\hline Non-Medicaid & $679(86)$ & $320(86)$ & $560(91)$ & \\
\hline
\end{tabular}

${ }^{*}$ Response rates to survey questions varied between 95 and $100 \%$. Percentages wer calculated based on number of respondents to the given question.

†Calculated using $\chi^{2}$ tests. was no difference among patients who experienced a near miss. Of note, a given patient frequently experienced more than one error.

\section{Medication errors by stage}

The majority of medication errors occurred during the ordering stage. Near misses occurred most often during ordering, followed by the administration stage. Ninety-four per cent of the 1205 medication errors (rate: $50 \%$ of $\mathrm{Rx}$; $95 \%$ CI 47 to $53 \%$ ) and $60 \%$ of the 464 near misses (rate: $12 \%$ of Rx; $95 \%$ CI 11 to $14 \%$ ) occurred at the ordering stage (table 3 ). Errors during administration represented $23 \%$ of near misses (5\% of Rx; $95 \%$ CI 4 to $6 \%$ ) but less than $5 \%$ of medication errors (3\% of Rx; $95 \%$ CI 2 to $3 \%)$.

\section{Medication errors by type}

Among near misses, dosing issues were most frequent and occurred in $8 \%$ of patients ( $95 \%$ CI 6 to $9 \%$ ) (table 3). Other common types of near misses were frequency issues (rate: $3 \%$ of patients; 95\% CI 2 to $4 \%$ ) and strength issues (rate: $3 \%$ of patients; $95 \%$ CI 2 to $4 \%$ ). Among medication errors, inappropriate abbreviations were most frequent (rate: $20 \%$ of patients; 95\% CI 18 to $22 \%$ ), followed by route issues (rate: $13 \%$ of patients; $95 \%$ CI 11 to $15 \%$ ), and amount issues (rate: $12 \%$ of

Table 3 Rates of medication errors

\begin{tabular}{|c|c|c|c|c|c|c|}
\hline & $\mathbf{n}$ & Percentage & $\begin{array}{l}\text { Rate per } \\
100 \text { patients }\end{array}$ & $95 \% \mathrm{Cl}^{*}$ & $\begin{array}{l}\text { Rate per } 100 \\
\text { prescriptions }\end{array}$ & $95 \% \mathrm{Cl}^{*}$ \\
\hline \multicolumn{7}{|c|}{ Medication errors with minimal potential for harm } \\
\hline Total & 1205 & 100 & 67.63 & 63.87 to 71.51 & 53.34 & 50.39 to 56.41 \\
\hline \multicolumn{7}{|l|}{ Stage of error } \\
\hline Ordering & 1135 & 94 & 63.69 & 60.06 to 67.47 & 50.24 & 47.38 to 53.22 \\
\hline Administering & 60 & 5.0 & 3.37 & 2.59 to 4.29 & 2.66 & 2.04 to 3.39 \\
\hline Dispensing & 5 & 0.41 & 0.28 & 0.10 to 0.60 & 0.22 & 0.08 to 0.48 \\
\hline Inappropriate abbreviation & 357 & 30 & 20.03 & 18.03 to 22.18 & 15.81 & 14.22 to 17.50 \\
\hline Route issues & 231 & 19 & 12.96 & 11.36 to 14.71 & 10.23 & 8.96 to 11.60 \\
\hline Amount issues & 205 & 17 & 11.50 & 10.00 to 13.15 & 9.07 & 7.89 to 10.37 \\
\hline Direction issues & 177 & 15 & 4.32 & 3.43 to 5.36 & 3.41 & 2.70 to 4.23 \\
\hline Strength issues & 121 & 10 & 6.79 & 5.65 to 8.07 & 5.36 & 4.46 to 6.37 \\
\hline \multicolumn{7}{|l|}{ Near misses } \\
\hline Total & 464 & 100 & 26.04 & 23.74 to 28.48 & 20.54 & 18.73 to 22.47 \\
\hline \multicolumn{7}{|l|}{ Stage of error } \\
\hline Ordering & 278 & 60 & 15.6 & 13.8 to 17.5 & 12.31 & 10.92 to 13.81 \\
\hline Administering & 107 & 23 & 6.0 & 4.9 to 7.2 & 4.74 & 3.89 to 5.69 \\
\hline Dispensing & 42 & 9.1 & 2.4 & 1.7 to 3.1 & 1.86 & 1.35 to 2.48 \\
\hline Transcribing & 30 & 6.5 & 1.7 & 1.2 to 2.4 & 1.33 & 0.91 to 1.86 \\
\hline Monitoring & 1 & 0.22 & 0.06 & 0.003 to 0.25 & 0.04 & 0.003 to 0.19 \\
\hline \multicolumn{7}{|l|}{ Type of error } \\
\hline Dose issues & 136 & 29 & 7.63 & 6.42 to 8.99 & 6.02 & 5.06 to 7.09 \\
\hline Other issues & 95 & 20 & 5.33 & 4.33 to 6.48 & 4.21 & 3.42 to 5.11 \\
\hline Frequency issues & 59 & 13 & 3.31 & 2.54 to 4.23 & 2.61 & 2.00 to 3.34 \\
\hline
\end{tabular}

*Rate calculations based on data from 1782 patients and 2259 prescriptions. 
Table 4 Medications categories associated with errors

\begin{tabular}{|c|c|c|c|c|c|c|}
\hline \multirow[b]{2}{*}{ Medication category } & \multicolumn{3}{|c|}{$\begin{array}{l}\text { Medication errors with minimal } \\
\text { potential for harm }\end{array}$} & \multicolumn{3}{|c|}{ Near misses } \\
\hline & $\mathbf{n}$ & $\begin{array}{l}\text { Percentage } \\
\text { of events* }\end{array}$ & $\begin{array}{l}\text { Percentage } \\
\text { of Rx } \dagger\end{array}$ & $\mathbf{n}$ & $\begin{array}{l}\text { Percentage of } \\
\text { events* }\end{array}$ & $\begin{array}{l}\text { Percentage } \\
\text { of Rx } \dagger\end{array}$ \\
\hline Penicillin or derivative & 501 & 42 & 72 & 91 & 20 & 13 \\
\hline $\begin{array}{l}\text { Bronchodilators, } \\
\text { inhaled }\end{array}$ & 59 & 5 & 30 & 45 & 10 & 23 \\
\hline Macrolides & 81 & 7 & 77 & 34 & 7 & 32 \\
\hline Steroids, topical & 49 & 4 & 47 & 26 & 6 & 25 \\
\hline $\begin{array}{l}\text { Ophthalmic } \\
\text { preparations }\end{array}$ & 87 & 7 & 79 & 42 & 9 & 38 \\
\hline Ibuprofen & 38 & 3 & 46 & 24 & 5 & 29 \\
\hline Steroids, inhaled & 29 & 2 & 36 & 25 & 5 & 31 \\
\hline Antifungal, topical & 42 & 3 & 57 & 13 & 3 & 18 \\
\hline Antihistamine & 36 & 3 & 42 & 16 & 3 & 19 \\
\hline Steroids, oral & 35 & 3 & 64 & 22 & 5 & 40 \\
\hline Emollients & 31 & 3 & 148 & 1 & 0.22 & 5 \\
\hline H2 blocker & - & - & & 1 & 0.55 & 6 \\
\hline Topical & 24 & 2 & 43 & 8 & 2 & 14 \\
\hline Leucotriene receptors & 23 & 2 & 88 & 3 & 0.65 & 12 \\
\hline Cephalosporins & 13 & 1 & 21 & 7 & 5 & 12 \\
\hline Acetaminophen & 15 & 1 & 38 & 18 & 4 & 45 \\
\hline Otit prep & 13 & 1 & 43 & 7 & 5 & 23 \\
\hline Gi meds & 12 & 1 & 300 & - & - & - \\
\hline Dermatologicals & 12 & 1 & 32 & 8 & 2 & 21 \\
\hline Antifungal oral & 10 & 1 & 24 & 13 & 3 & 31 \\
\hline Vitamins & 10 & 1 & 40 & 7 & 2 & 28 \\
\hline Antimalarial & 8 & 1 & 160 & & & \\
\hline Topical anaesthetic & 7 & 1 & 2 & 2 & 0.43 & 7 \\
\hline Bronchodilator oral & 1 & 0.08 & 8 & 5 & 1 & 42 \\
\hline Antituberculosis & 5 & 0.41 & 71 & 4 & 0.86 & 67 \\
\hline Antitussive & - & - & - & 4 & 0.86 & 15 \\
\hline Decongestant & 5 & 0.41 & 71 & 4 & 0.86 & 57 \\
\hline Antiviral & - & - & - & 1 & 0.22 & 25 \\
\hline Laxative & 5 & 0.41 & 25 & 4 & 0.86 & 20 \\
\hline Analgesic & - & - & & 6 & 1 & 67 \\
\hline Other meds & 24 & 2 & 126 & 5 & 1 & 26 \\
\hline Proton pump inhibitor & - & - & - & - & - & - \\
\hline Stimulants & 6 & 0.50 & 29 & 4 & 0.86 & 19 \\
\hline Sulfa & 4 & 0.33 & 33 & 2 & 0.43 & 15 \\
\hline Scabicides & 1 & 0.08 & 14 & 3 & 0.65 & 9 \\
\hline Antihelminitics & 2 & 0.17 & 50 & 2 & 0.43 & 50 \\
\hline Epinehprine & 5 & 0.41 & 38 & 2 & 0.43 & 15 \\
\hline$\beta$ blocker & - & - & - & 1 & 0.22 & 100 \\
\hline Cerumenolytic & - & - & - & 1 & 0.22 & 33 \\
\hline Muscle relaxant & - & - & - & 1 & 0.22 & 50 \\
\hline Normal saline & 3 & 0.25 & 11 & & & \\
\hline Antitussive & 2 & 0.17 & 7 & & & \\
\hline Thyroid agent & 2 & 0.17 & 200 & & & \\
\hline Immunologicals, topical & 2 & 0.07 & 67 & & & \\
\hline Nasal spray & 1 & 0.08 & 7 & & & \\
\hline Iron & 1 & 0.08 & 20 & & & \\
\hline Haemostatic & 1 & 0.08 & 50 & & & \\
\hline $\begin{array}{l}\text { Topical oestrogen } \\
\text { cream }\end{array}$ & & & & 2 & 0.43 & 22 \\
\hline
\end{tabular}

patients; $95 \%$ CI 10 to $13 \%$ ). The methodology employed in this study has been used in multiple previous studies. ${ }^{2} 5$ - 6 8-10 Throughout all of this work, inappropriate abbreviations were consistently defined as errors. We agree that many had minimal potential for harm but are deviations from practice, and therefore, we have categorised them as errors. The rate of dosing issues was similar for medication errors (rate: $6 \%$ of patients; $95 \%$ CI 5 to $7 \%$ ) and near misses.

\section{Medication errors by drug category}

A notable portion of medication errors (42\%) and near misses $(20 \%)$ involved penicillin or its derivatives (table 4$)$. Some groups 
of medications, including emollients, gastrointestinal medications, antimalarial drugs and thyroid agents averaged more than one mistake per prescription.

\section{Sources of errors}

Illegibility and weight-related errors were prevalent sources of errors, and we report them separately from medication errors. We found 670 illegibility errors (table 5). Of the illegibility errors, 489 had illegible physician signatures. Errors in documentation of patients' weight were nearly as common (667 errors). The most frequent weight-related errors were omission of weight information (73\%) and omission of weight units (27\%).

\section{Rule violations}

Of the 212 detected rule violations, 'as needed' (PRN) without indication (48\%) and unspecified length of treatment (with correct dispensing amount; 43\%) were most frequent.

\section{DISCUSSION}

Medication errors were extremely frequent in this study: half of prescriptions had errors, and a fifth had errors with the potential for harm. This study employed the methodology used in several previous studies, suggesting that high rates of errors found in this study were not due to methodological differences. ${ }^{2} 568-10$ Eighty-five per cent of all errors occurred in the ordering process. In addition, there were many administration errors among near misses.

It is still unclear if non-harmful errors are similar to or predictive of harmful errors. Therefore, we undertook this epidemiological study to understand the differences between non-harmful and potentially harmful medication errors and to target areas for improvement. The most frequent causes of errors with minimal potential for harm were inappropriate abbreviations, followed by route and amount issues. In contrast, the most frequent causes of near misses were errors in dosing,

Table 5 Frequent causes of medication errors with minimal potential for harm

\begin{tabular}{lc}
\hline Category of error & $\begin{array}{l}\text { Medication errors with } \\
\text { minimal potential for } \\
\text { harm (n (\%)) }\end{array}$ \\
\hline Illegibility errors & $670(100)$ \\
MD signature illegible & $489(73)$ \\
Illegible strength or strength units & $43(6)$ \\
Illegible patient name & $30(5)$ \\
Illegible duration & $20(3)$ \\
Illegible dispense amount & $21(3)$ \\
Illegible weight & $12(2)$ \\
Other & $11(2)$ \\
Illegible date & $10(1)$ \\
Illegible frequency or frequency units & $9(1)$ \\
Illegible dose & $8(1)$ \\
Illegible directions for use & $8(1)$ \\
Patient name spelled wrong & $7(1)$ \\
Illegible script & $1(<1)$ \\
First name initial only & $1(<1)$ \\
Weight errors & $667(100)$ \\
Omitted & $487(73)$ \\
Units missing & $178(27)$ \\
Wrong & $2(<1)$ \\
Date errors & $72(100)$ \\
Missing & $43(60)$ \\
Wrong & $23(32)$ \\
Other & $6(8)$ \\
\hline
\end{tabular}

frequency and other issues such as drug-allergy and drug-drug interactions. Therefore, the results of this study appear to indicate a difference between harmful and potentially harmful medication errors, suggesting that different strategies may need to be employed for each type of error.

In the paediatric outpatient setting, the rates of near misses and errors with minimal potential for harm far exceeded the rates of comparable errors in the adult setting. ${ }^{8}$ Near misses, if not addressed, can lead to significant patient harm, and the high rates seen in the paediatric outpatient setting are cause for concern. Compared with a similar adult study, the rate of ordering-related near misses was four times higher in children (12.3 vs $3.3 \%$ ), and the rate of errors with minimal potential for harm was more than 12 times higher (50.2\% vs $4.2 \%) .^{5}$ The many calculations required in paediatrics to do weight-based dosing may be an important factor contributing to the high rates of prescribing near misses. Of the near misses, $23 \%$ occurred at the administration stage, which is similar to paediatric ambulatory ADEs. ${ }^{6}$ Targeted prevention strategies to decrease errors at this stage are particularly important in paediatrics, as there are few proven interventions to address administration errors.

Electronic prescribing (e-prescribing) with clinical decision support is a widely noted strategy for reducing medication errors. ${ }^{10}$ E-prescribing systems ensure that prescriptions are legible, complete and in a standard format. Most e-prescribing systems provide decision support, such as default doses, which would further reduce errors. ${ }^{11}$ Despite tremendous promise, e-prescribing is not a panacea for medication ordering errors. Important considerations include cost, physician resistance to changes in workflow, lack of technological support and difficulties in choosing among systems and integrating with other systems. ${ }^{12} 13$

This study found a high rate of illegibility errors which may be important because of potentially significant misinterpretation of prescriptions or delays in a patient obtaining the intended medication. For example, when there is a problem in a prescription with an illegible prescriber's signature, the pharmacist may need to contact the patient for their prescriber's name, which could result in delays in obtaining the medication.

Our study has several limitations. Over $50 \%$ of prescribers in the study were residents. It is unknown whether resident prescribing patterns are different from non-resident prescribers. It should also be noted that residents tend to see a higher Medicaid population, and it is unclear whether Medicaid insured children have higher rates of medication errors. We obtained data from six office practices in Massachusetts. Although the practices served diverse populations, the generalisability of the study may be limited by the number of practices. In addition, physicians were not blinded to the purpose of the study, and physician awareness could have affected the incidence and detection of errors. This study demonstrates that medication errors with minimal potential for harm and near misses were very common in the paediatric ambulatory setting. Most medication errors occurred during the ordering stage. The vast majority could have been intercepted by e-prescribing systems. Results of this study may inform national discussions regarding technologies that promote medication safety among children, though further studies are urgently needed.

Funding This project was supported by the Agency for Healthcare Research and Quality (P01-HS11534), Rockville, Maryland.

Competing interests None.

Ethics approval Ethics approval was provided by the Partners Human Research Committee of the Partners Healthcare System of Boston, Massachusetts, USA.

Provenance and peer review Not commissioned; externally peer reviewed. 


\section{REFERENCES}

1. Anon. Public Opinion of Patient Safety Issues Research Findings: National Patient Safety Foundation at the AMA. Louis Harris and Associates, 1997. www.npsf.org/ pdf/r/1997/survey.pdf

2. Kaushal R, Bates DW, Landrigan $C$, et al. Medication errors and adverse drug events in pediatric inpatients. JAMA 2001;285:2114-20.

3. Bates DW, Boyle DL, Vander Vliet MB, et al. Relationship between medication errors and adverse drug events. J Gen Intern Med 1995;10:199-205.

4. Cypress BK. Drug utilization in office visits to primary care physicians: national ambulatory medical care survey, 1980. Adv Data 1982;86:1-16.

5. Gandhi TK, Weingart SN, Seger AC, et al. Outpatient prescribing errors and the impact of computerized prescribing. J Gen Intern Med 2005;20:837-41.

6. Kaushal R, Goldmann D, Keohane $\mathrm{C}$, et al. Adverse drug events and near misses in pediatric outpatients. Ambul Pediatr 2007;7:383-9.

7. Kohn LT, Corrigan JM, Donaldson MS. To Err Is Human: Building a Safer Health System. Washington, DC: National Academy Press, 1999.
8. Gandhi TK, Weingart SN, Borus J, et al. Adverse drug events in ambulatory care. N Engl J Med 2003;348:1556-64.

9. Bates DW, Cullen DJ, Laird N, et al. Incidence of adverse drug events and potential adverse drug events. Implications for prevention. ADE Prevention Study Group. JAMA 1995;274:29-34.

10. Bates DW, Leape LL, Cullen DJ, et al. Effect of computerized physician order entry and a team intervention on prevention of serious medication errors. JAMA 1998;280:1311-16

11. Eslami S, Abu-Hanna A, de Keizer NF. Evaluation of outpatient computerized physician medication order entry systems: a systematic review. J Am Med Inform Assoc 2007;14:400-6.

12. Poon EG, Blumenthal D, Jaggi T, et al. Overcoming barriers to adopting and implementing computerized physician order entry systems in US hospitals. Health Aff (Millwood) 2004;23:184-90.

13. Simon SR, Kaushal R, Cleary PD, et al. Correlates of electronic health record adoption in office practices: a statewide survey. J Am Med Inform Assoc 2007:14:110-17. 